\title{
Characterization of Polyacrylamide based Superabsorbent Polymers for potential use in PC Matrices with Supplementary Cementitious Materials
}

\author{
Fernando C.R. Almeida *, Rohollah Rostami, and Agnieszka J Klemm \\ School of Engineering and Built Environment, Glasgow Caledonian University, UK
}

\begin{abstract}
This paper compares three types of polyacrylamide based Superabsorbent Polymers (SAP) with different water absorption capacities for potential application in Portland cement composites. The analysed matrices contain Supplementary Cementitious Materials (SCM) such as ground granulated blast-furnace slag (GGBS), fly ash (FA type F), silica fume (SF) and lime (NHL 5). SAPs were characterized in terms of shape, size and molecular structure by the Laser Diffraction, SEM, and the Raman Spectroscopy techniques. Kinetics and capacity of SAPs absorption in different environments (deionised water, PC solution and various PC-SCMs solutions) were evaluated by the tea-bag method. $\mathrm{pH}$ of all solutions was determined after 24 hours. The effect of different SCMs on SAPs sorption behaviour has been presented. The experimental results show that SAPs do not affect $\mathrm{pH}$ of cementitious solutions. However, SCMs addition reduces SAPs' absorption capacity and increase their desorption features. This is related not only to the type of SCM, but also to the level of substitution.
\end{abstract}

\section{Introduction}

The use of cement-based materials containing Supplementary Cementitious Materials (SCMs) in concrete manufacture has significantly increased and become worldwide popular (Lothenbach et al. 2011; Scrivener et al. 2015; Siddique and Khan 2011). However, there is still a major concern about various deteriorative processes, including early cracking induced by self-desiccation processes and the following autogenous shrinkage (Bouasker et al. 2014; Ghourchian et al. 2018; Holt and Leivo 2004; Wyrzykowski and Lura 2016). In an effort to reduce this cracking susceptibility, Superabsorbent polymers (SAPs) have been proved a promising internal curing agent for concrete and mortars (Bentz and Jensen 2004; Jensen and Hansen 2001, 2002; Mechtcherine et al. 2013; Mechtcherine and Reinhardt 2012; Mignon et al. 2017; Snoeck et al. 2015). Also, SAPs are able to control water supply in fresh and hardened state, and hence to help extended hydration reactions of SCMs (Almeida and Klemm 2018; Beushausen et al. 2014; Klemm and Sikora 2013; Snoeck et al. 2014). Moreover, absorption capacities and kinetics of SAPs' ab- desorption have a critical impact on concrete mix design. Their sorption performances may differ significantly, depending not only on the physical and chemical characteristics of polymer, but also on the ionic composition of pore solution (Mechtcherine and Reinhardt 2012; Schröfl et al. 2017). Thus, different interactions may take place between SAPs and various cementitious systems modified by SCMs. Despite a systematic drawback on the residual interparticle (capillary) solution, the tea-bag gravimetric method is the most common and widely accepted quantification technique for SAP's sorptivity assessment (Schröfl et al. 2017). Therefore, this paper analyses the effects of different SCMs, such as ground granulated blast-furnace slag (GGBS), fly ash (FA-F), silica fume (SF), and lime (NHL5), on the absorption behaviour of three types of SAPs in filtrate solutions. The main aim of this study was to illustrate the importance of polymers sorption characteristics in the selection process of SAPs for different cementitious matrices.

\section{Methodology}

Three types of polyacrylamide based superabsorbent polymers (SAP 1, 2 and 3) with different water absorption capacities have been studied.

Shapes and sizes of SAPs have been characterized by the Laser Diffraction and the Scanning Electron Microscopy techniques. Polymers' structural patterns have been verified by the Raman Spectrometry. A polyacrylamide base (non-ionic water soluble (C3H5NO)n, Sigma Aldrich 92560) has been used to compare the structure of SAPs samples.

SAPs sorption has been characterized in different solutions, including different types of Supplementary Cementitious Materials (SCM's): deionized water (DI),

* Corresponding author: Fernando.Almeida@gcu.ac.uk 
ordinary Portland cement (PC) (CEM I 52.5N), ground granulated blast-furnace slag (GGBS), fly ash type $\mathrm{F}$ (FA), silica fume (SF) and lime (natural hydraulic lime NHL-5). Table 1 shows chemical compositions and selected physical characteristics of the supplementary cementitious materials.

Table 1. Chemical and physical characterization of binders.

\begin{tabular}{l|llllll}
\hline Parameter & Unit & PC & GGBS & FA & SF & Lime \\
\hline $\mathrm{CaO}$ & $\mathrm{wt} \%$ & 62.4 & 38.5 & 18.1 & 0.4 & 54.1 \\
$\mathrm{SiO} 2$ & $\mathrm{wt} \%$ & 20.1 & 34.5 & 38.8 & 93.7 & 12.7 \\
$\mathrm{Al} 2 \mathrm{O} 3$ & $\mathrm{wt} \%$ & 4.9 & 13.4 & 14.7 & 0.5 & 5.2 \\
$\mathrm{MgO}$ & $\mathrm{wt} \%$ & 2.2 & 9.7 & 3.3 & 0.4 & 7.7 \\
$\mathrm{Fe} 2 \mathrm{O} 3$ & $\mathrm{wt} \%$ & 2.7 & 0.2 & 19.5 & 1.1 & 1.4 \\
$\mathrm{SO} 3$ & $\mathrm{wt} \%$ & 3.2 & 0.4 & 1.5 & 0.3 & 2.1 \\
$\mathrm{Na} 2 \mathrm{O}$ & $\mathrm{wt} \%$ & 0.3 & 0.2 & - & 0.3 & 0.3 \\
$\mathrm{~K} 2 \mathrm{O}$ & $\mathrm{wt} \%$ & 0.6 & 0.6 & 1.8 & 0.9 & 1.3 \\
$\mathrm{MnO}$ & $\mathrm{wt} \%$ & - & 0.2 & 0.2 & - & - \\
$\mathrm{Cl}-$ & $\mathrm{wt} \%$ & 0.06 & 0.02 & - & - & - \\
$\mathrm{LOI}$ & $\mathrm{wt} \%$ & 2.77 & 0.64 & 0.07 & 2.5 & 0.15 \\
Specific & & & & & & \\
surface & $\mathrm{m} 2 / \mathrm{kg}$ & 410 & 390 & 335 & 22500 & 750 \\
\hline
\end{tabular}

Filtrate solutions with different proportions of SCMs (Table 2) have been prepared in a water/binder ratio of 5 (Mechtcherine et al. 2018).

Table 2. Composition of filtrate solutions with SCM's (in grams).

\begin{tabular}{c|cccccc}
\hline $\begin{array}{c}\text { Filtrate } \\
\text { solution }\end{array}$ & $D I$ & $P C$ & $G G B S$ & $F A$ & SF & Lime \\
\hline DI & 500 & - & - & - & - & - \\
PC & 500 & 100 & - & - & - & - \\
$25 \%$ GGBS & 500 & 75 & 25 & - & - & - \\
$50 \%$ GGBS & 500 & 50 & 50 & - & - & - \\
$75 \%$ GGBS & 500 & 25 & 75 & - & - & - \\
$25 \%$ FA & 500 & 75 & - & 25 & - & - \\
$50 \%$ FA & 500 & 50 & - & 50 & - & - \\
$75 \%$ FA & 500 & 25 & - & 75 & - & - \\
$25 \%$ SF & 500 & 75 & - & - & 25 & - \\
$50 \%$ SF & 500 & 50 & - & - & 50 & - \\
$75 \%$ SF & 500 & 25 & - & - & 75 & - \\
$25 \%$ Lime & 500 & 75 & - & - & - & 25 \\
$50 \%$ Lime & 500 & 50 & - & - & - & 50 \\
$75 \%$ Lime & 500 & 25 & - & - & - & 75 \\
\hline
\end{tabular}

Binders have been immersed and stirred in deionised water for 24 hours. After this time the binder slurry was filtrated to obtain the required filtrate solution (Mechtcherine et al. 2018; Schröfl et al. 2017).

Kinetics of absorption and water absorption capacity (WAC) of SAP have been evaluated by the teabag method (Schroefl et al. 2015; Schröfl et al. 2012, 2017). Masses of SAP gel were recorded at 1, 5, 10, 30, 60, 180 and 1440 min after tea-bag immersion. WACs were calculated using the Equation 1 and expressed in grams of water per gram of dry SAP.

$$
W A C=\left(m_{2}-m_{1}\right) / m_{1}
$$

Where $\mathrm{m}_{1}=$ weight of dry SAP; and $\mathrm{m}_{2}=$ weight of water-swollen sample.
$\mathrm{pH}$ of SAPs solutions (and plain solutions without SAPs) have been recorded at $24 \mathrm{~h}$ (at the end of tea-bag test).

All tests were in triplicates and carried out under normal laboratory conditions $\left(\mathrm{T}=21 \pm 2{ }^{\circ} \mathrm{C}\right.$ and $\left.\mathrm{RH}=40 \pm 5 \%\right)$.

\section{Results and Discussions}

Figure 1 shows results of particle size distribution of SAPs samples by the Laser Diffractometry.

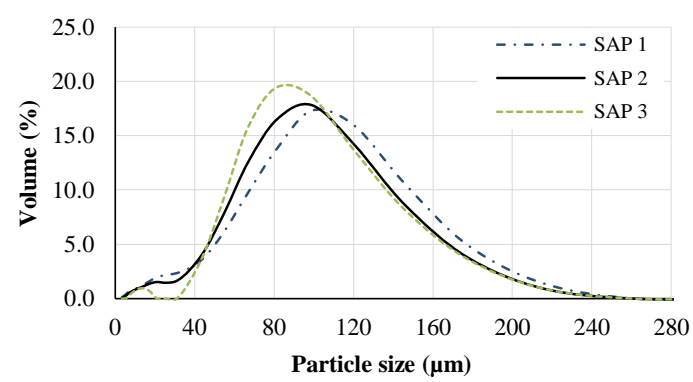

Fig. 1. Particle size distribution of SAPs.

Mode values for each polymer were: SAP $1=102.5 \mu \mathrm{m}$ $>$ SAP $2=95.2 \mu \mathrm{m}>$ SAP $3=85.7 \mu \mathrm{m}$.

Despite some small differences in particle distributions, all samples had particles in the same size range, predominantly between 20 and $150 \mu \mathrm{m}$. This result has been confirmed by SEM analysis of the studied polymers (Fig. 2). SAPs particles were of irregular shapes due to the production processes. Polymerization of the aqueous monomer solution in reactor, followed by crushing of the gel into small pieces, results in particles with irregular shapes, like broken glass visible under a microscope (Mechtcherine and Reinhardt 2012).

Figure 3 shows Raman spectra which confirm the base polymer being polyacrylamide. Any differences in sorption performances, however, could be attributed to their respective particular monomers.

Figure 4 shows results of SAPs absorption in DI water and PC solution.

Overall, cementitious solutions reduced significantly water absorption capacity of polymers. In the first $3 \mathrm{~h}$, WAC values were around 250, 275 and $355 \mathrm{~g} / \mathrm{g}$ in DI water for SAPs 1, 2 and 3, respectively. In PC solutions, those values were significantly reduced to 37,38 and 45 $\mathrm{g} / \mathrm{g}$. Considerable reduction in overall swelling capacity (compared to DI water) is due to the presence of dissolved cations in binder filtrates, especially $\mathrm{K}+, \mathrm{Na}+$, $\mathrm{Mg} 2+$ and $\mathrm{Ca} 2+$ (Mignon et al. 2015). 


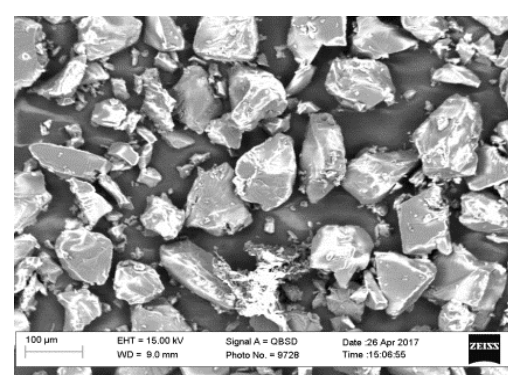

Fig. 2. Micrographs of SAPs 1, 2 and 3 respectively.

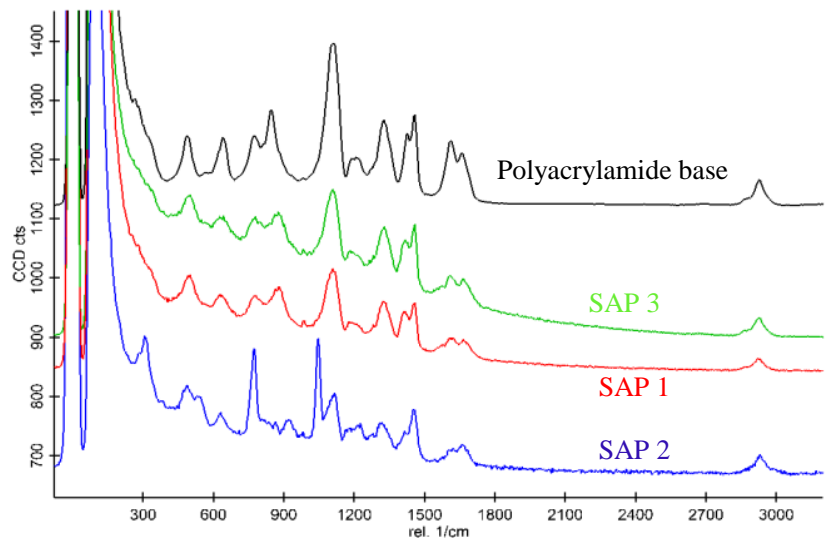

Fig. 3. Comparison of molecular structure of the studied SAPs and polyacrylamide by Raman spectroscopy.
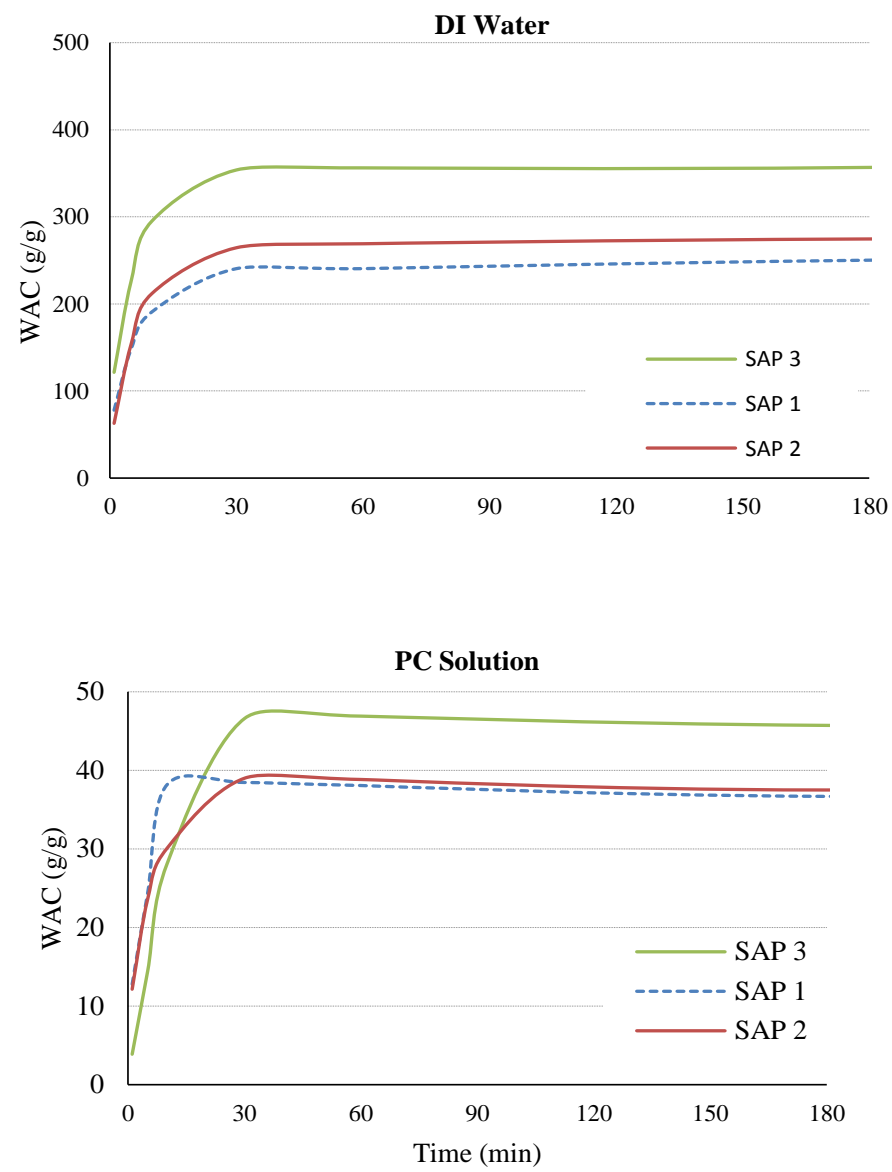

Moreover, absorption kinetics were different for all SAPs after longer period of time (up to $1 \mathrm{~h}$ ). In DI water, SAP 1 and 3 kept absorbing significant amount of water, with an increment of $28 \%$ and $20 \%$ of the initial absorption, respectively. Absorption by SAP 2, in turn, increased by $7 \%$ only. In PC solution, all SAPs started to release water after the initial absorption peak (before $30 \mathrm{~min})$. However, SAP 2 had the ability to recover itself to the initial max WAC, while overall WAC of SAP 1 and 3 were considerably reduced.

Figure 5 shows WAC of the polymers in GGBS solutions with different levels of substitution. SAP 3 had the greatest WAC followed by SAP 2 and SAP 1 . However, as in PC solution, WAC of SAP 2 seems to be unchanged over the time, while SAP 1 and 3 showed a significant release of water, especially for high GGBS contents $(>50 \%)$. Final WAC values (at 24 hours) reached approximately 33, 37 and $40 \mathrm{~g} / \mathrm{g}$ in $25 \%$ GGBS solution, respectively for SAP 1, 2 and 3.
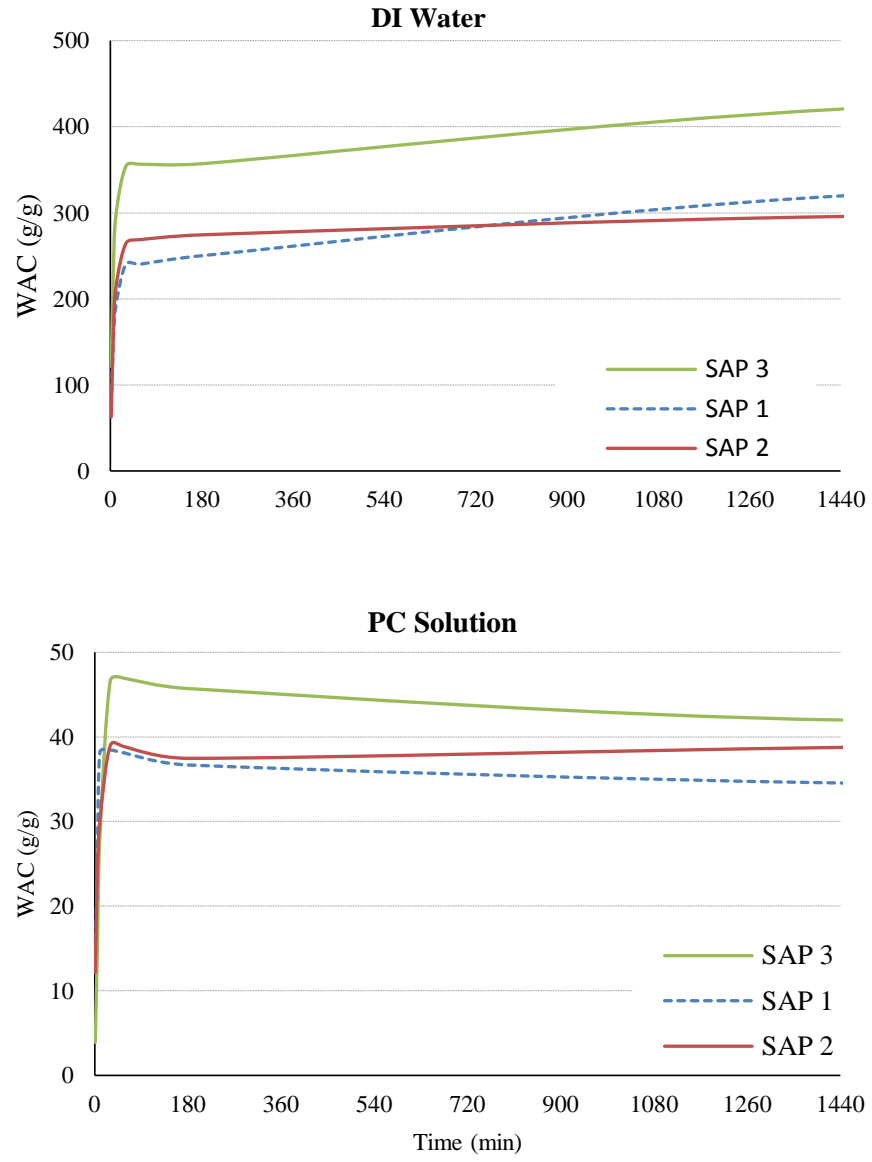

Fig. 4. Comparison of SAPs absorbency (left: up to 3h; right: up to 1 day) in deionised water (top) and PC solution (bottom). 
In $75 \%$ GGBS solution, these values dropped to 28,37 and $37 \mathrm{~g} / \mathrm{g}$ respectively. Thus, apart from SAP C, the higher GGBS level, the lower WACs for SAPs 1 and 3.Figure 6 presents results of WAC in fly ash (FA) solutions with different levels of replacements. Overall, the higher FA content the lower WAC values. Similar behavior of SAP absorption was recorded for GGBS solutions: SAP 1 and 3 had much greater desorption than SAP 2 over the time. In particular for FA contents above

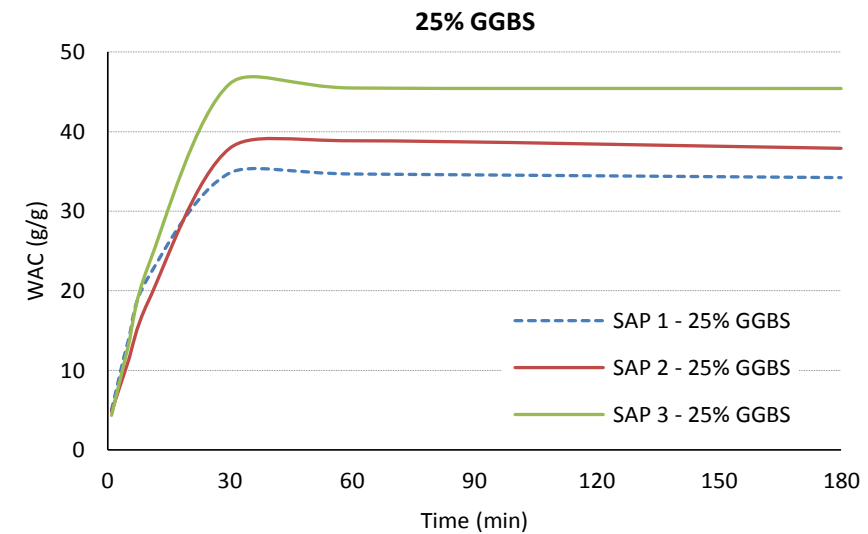

$50 \%$ GGBS

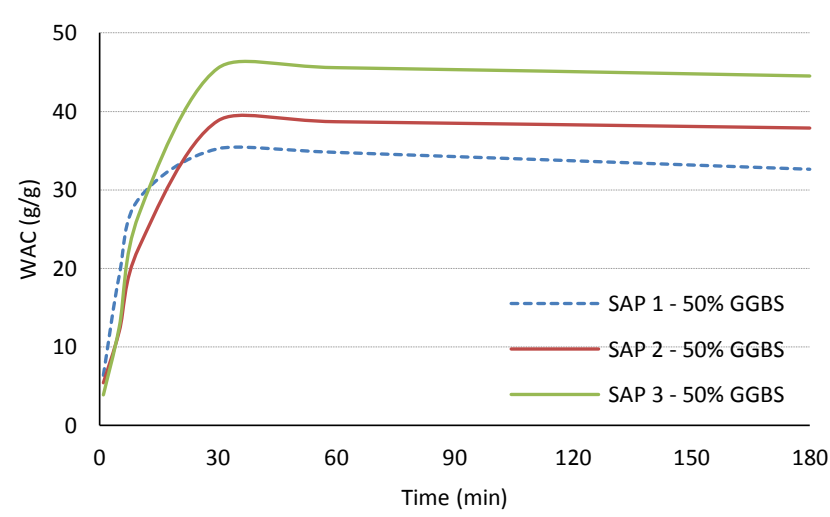

75\% GGBS

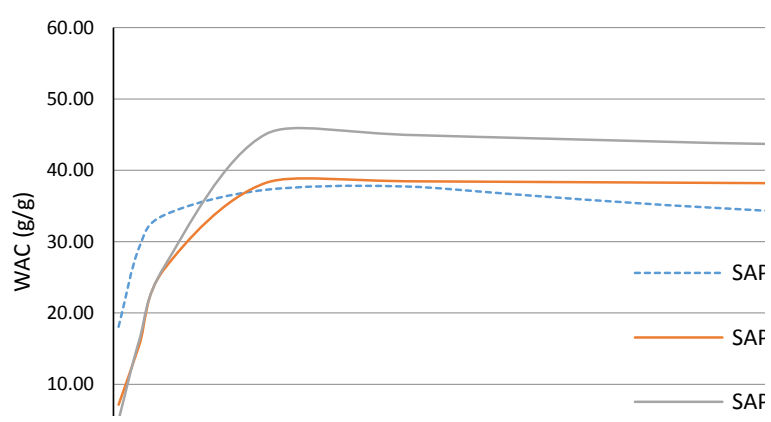

$50 \%$, SAP 3 had reached similar WAC value to that of SAP 2 at 1-day, even that the first polymer had the highest initial absorption capacity. Moreover, SAPs usually showed lower absorption capacity values in FA solutions when compared to GGBS solutions. Respectively for polymers 1, 2 and 3, WACs were about 23,33 and $33 \mathrm{~g} / \mathrm{g}$ in $75 \% \mathrm{FA}$ solution at $24 \mathrm{~h}$. Figure 7 shows WAC results of SAPs in silica fume (SF) solutions. As in PC solution, SF addition resulted in
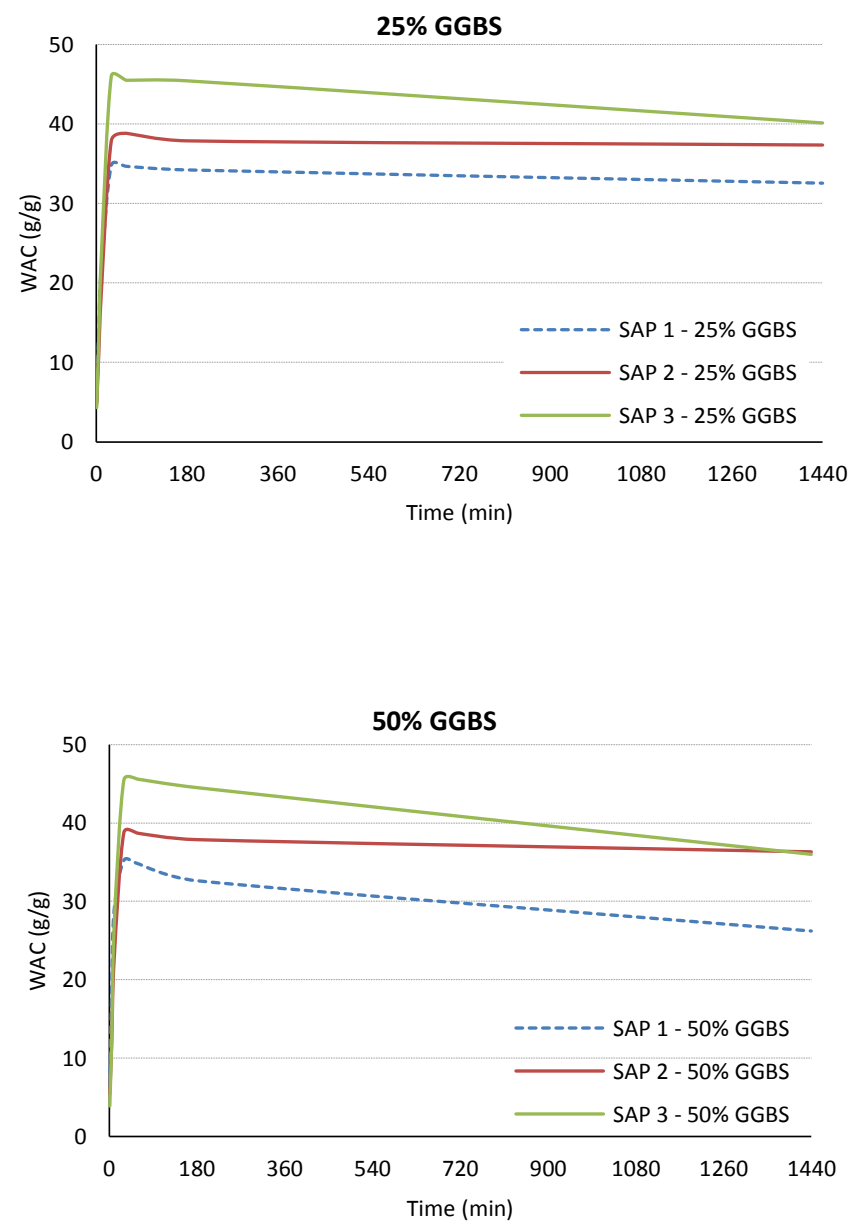

75\% GGBS

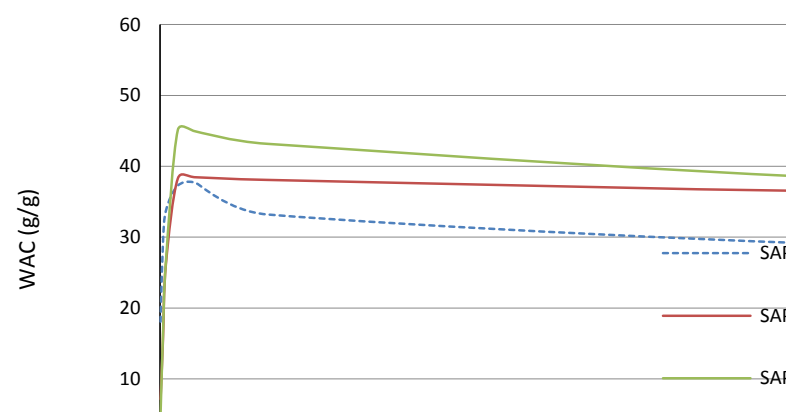

Fig. 5. Comparison of SAPs absorbency (left: up to 3h; right: up to 1 day) in different GGBS contents. 
absorption capacity values of SAP $3>$ SAP $2>$ SAP A for all levels of substitution.

Again, SAP 2 showed low or no desorption (regardless SF content), and water storage ability of SAP 1 and 3 were considerably reduced.

$25 \%$ FA

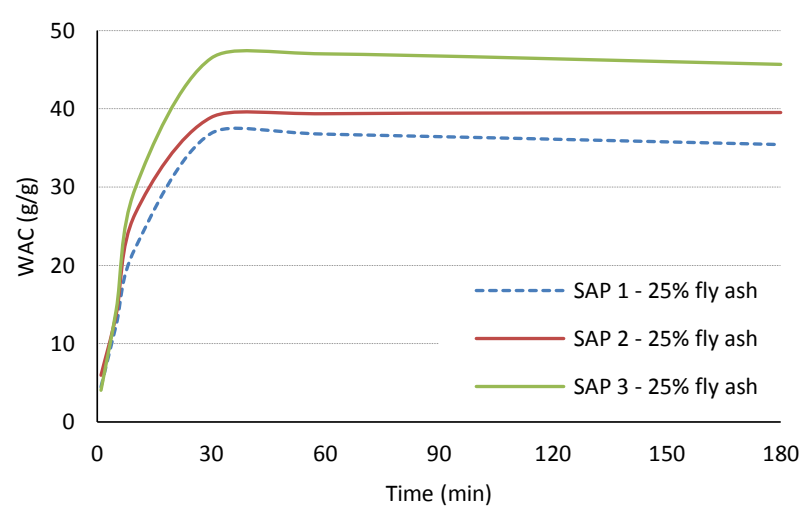

$50 \%$ FA

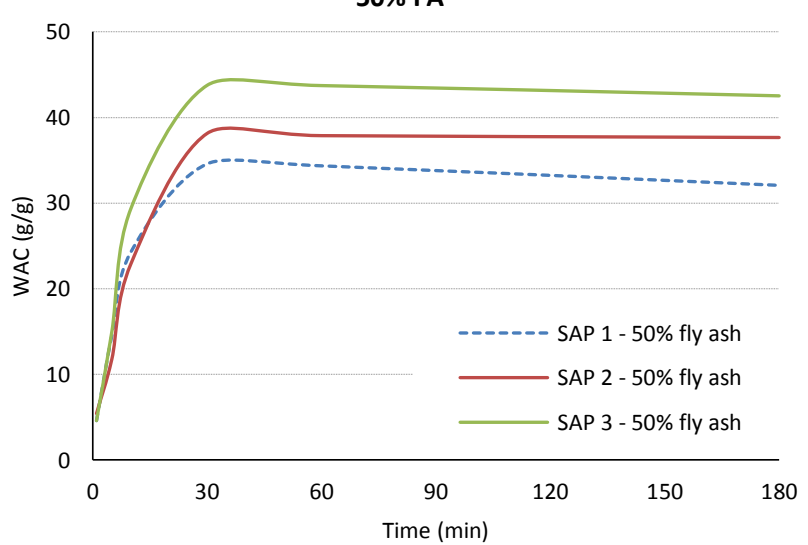

$75 \%$ FA

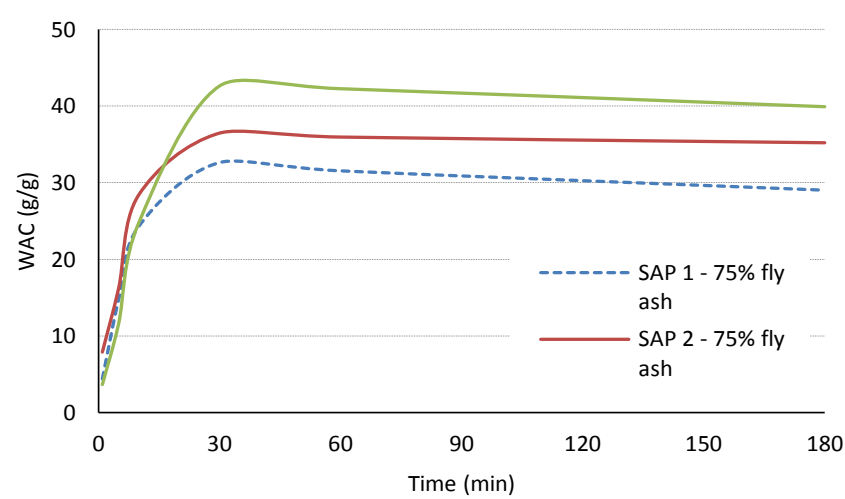

In particular for low SF content (25\%), final WACs were about 29,37 and $42 \mathrm{~g} / \mathrm{g}$ for SAPs 1,2 and 3 at $24 \mathrm{~h}$. At $75 \% \mathrm{SF}$, these values reached 32,37 and $39 \mathrm{~g} / \mathrm{g}$ for the same polymers. In this last case, SAP 1 performed differently from the other SCM's: the higher SF contents, the higher WAC.
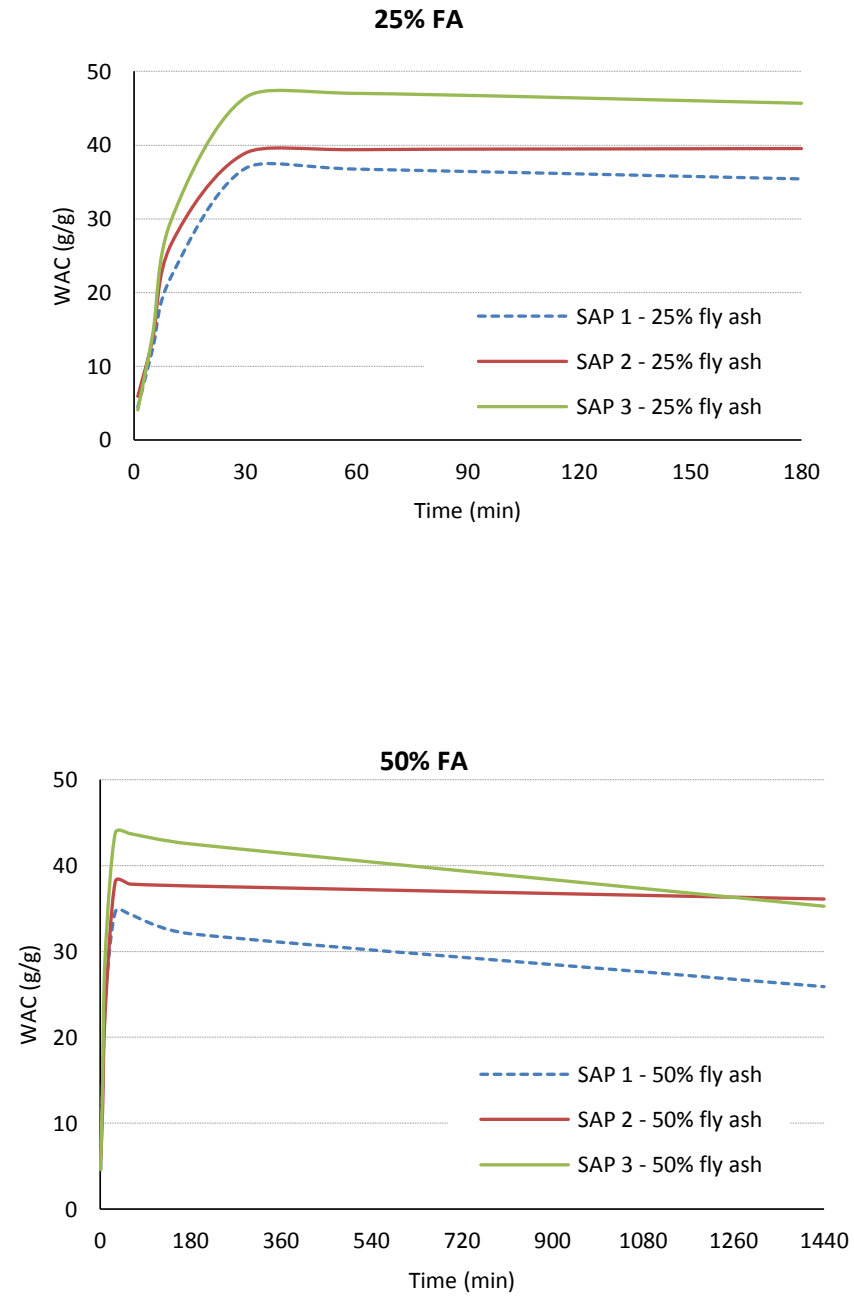

75\% FA

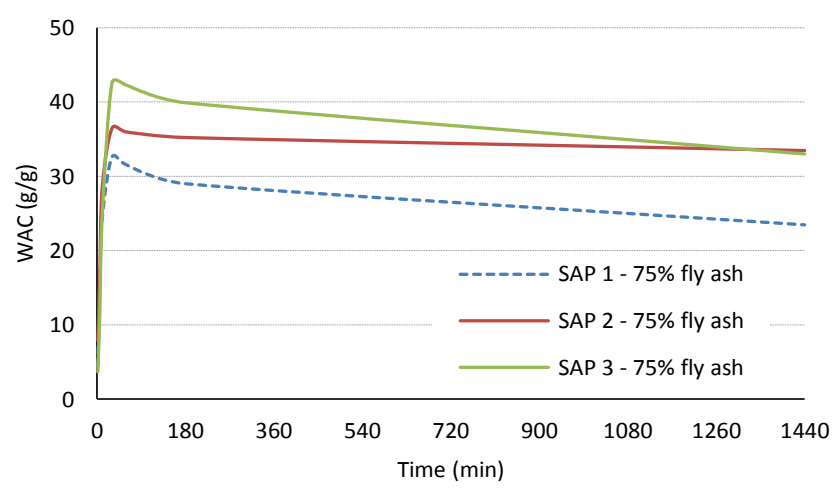

Fig. 6. Comparison of SAPs absorbency (left: up to 3h; right: up to 1 day) in different FA contents. 

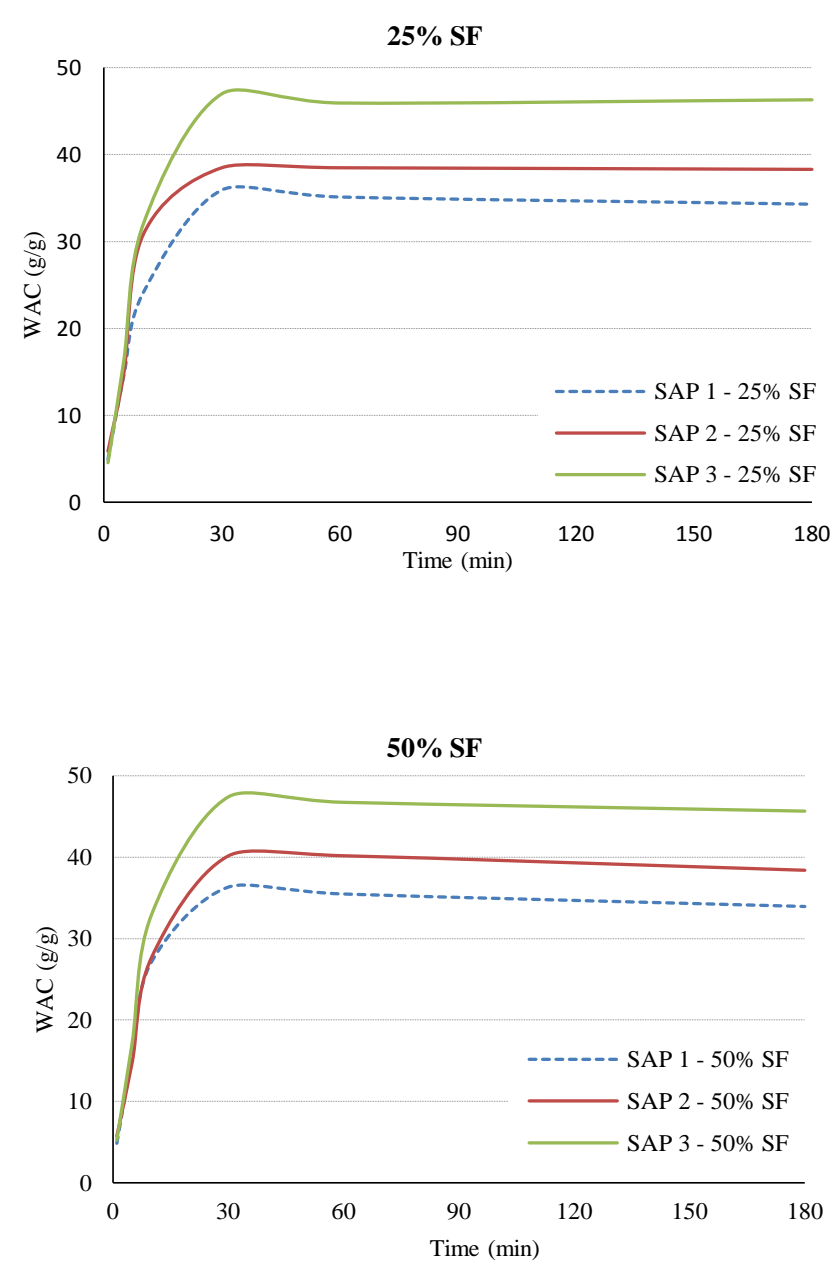

$75 \% \mathrm{SF}$

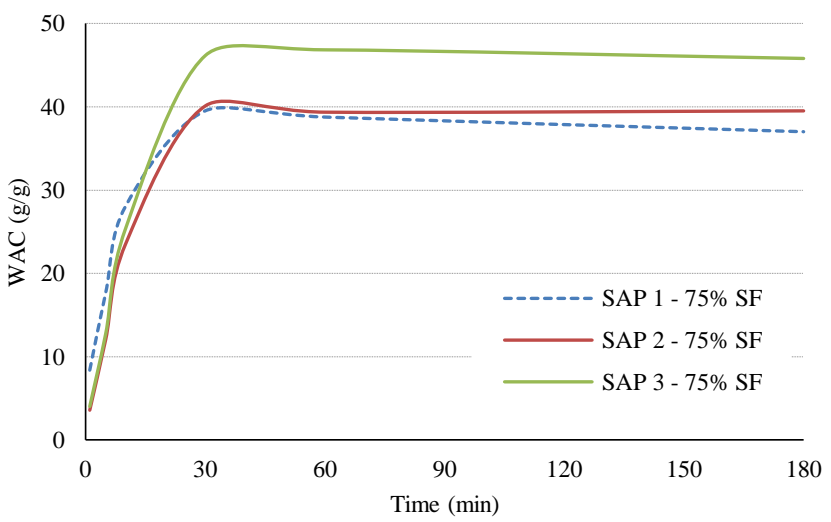

$25 \% \mathrm{SF}$

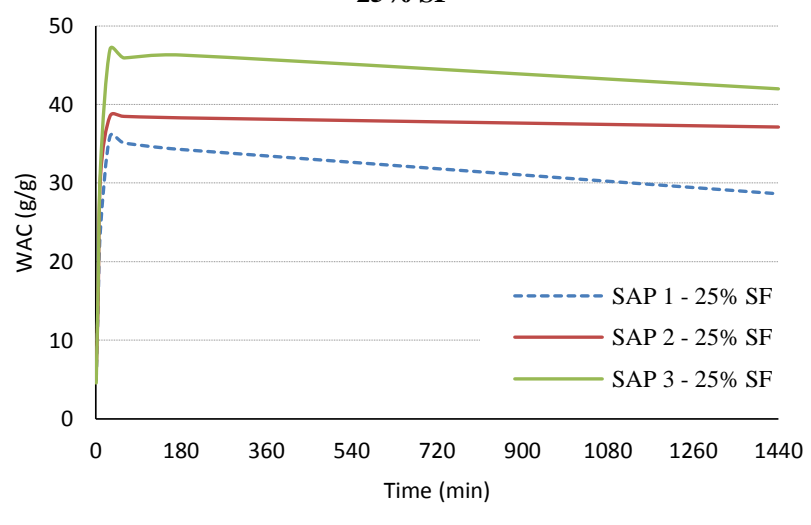

$\mathbf{5 0 \%} \mathrm{SF}$

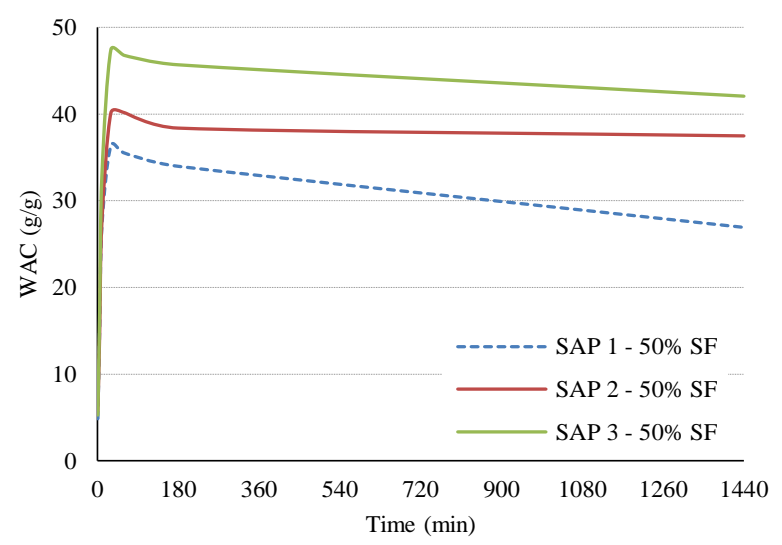

$75 \% \mathrm{SF}$

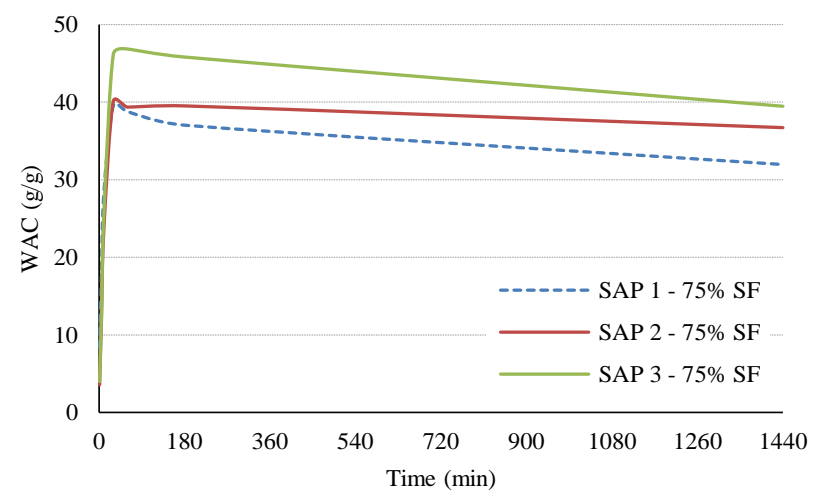

Fig. 7. Comparison of SAPs absorbency (left: up to 3h; right: up to 1 day) in different SF contents

Figure 8 shows WAC results for lime solutions in different contents. Overall, SAP 3 had the highest absorption values, followed by SAP 2 and then, SAP 1. However, their performances over the time varied for different amount of lime addition. Although SAP 1 and 2 indicated a comparable behaviours for high lime contents during the initial 3 hours, after 24 hours WAC of SAP 2 showed a similar tendency to SAP 3. Solutions with $25 \%$ of lime resulted in WACs of 35,38 and $42 \mathrm{~g} / \mathrm{g}$ for SAPs 1, 2 and 3 at 24h. However, at $75 \%$ lime, WACs values were about $36 \mathrm{~g} / \mathrm{g}$ for both 2 and 3 polymers, and $32 \mathrm{~g} / \mathrm{g}$ for SAP 1. 


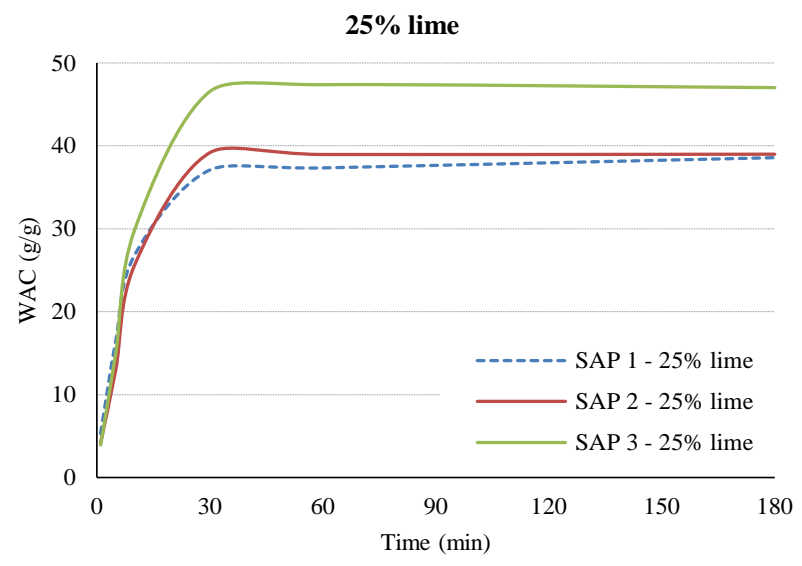

$50 \%$ lime
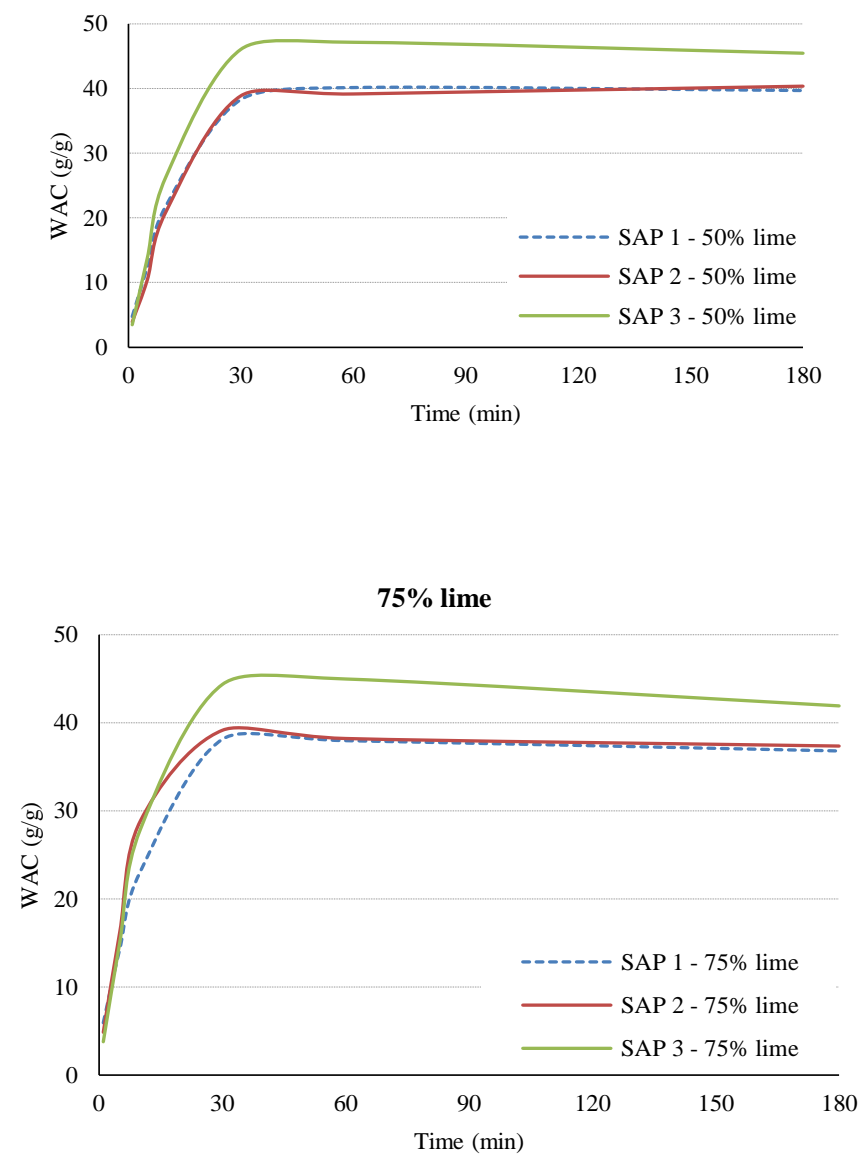

$25 \%$ lime

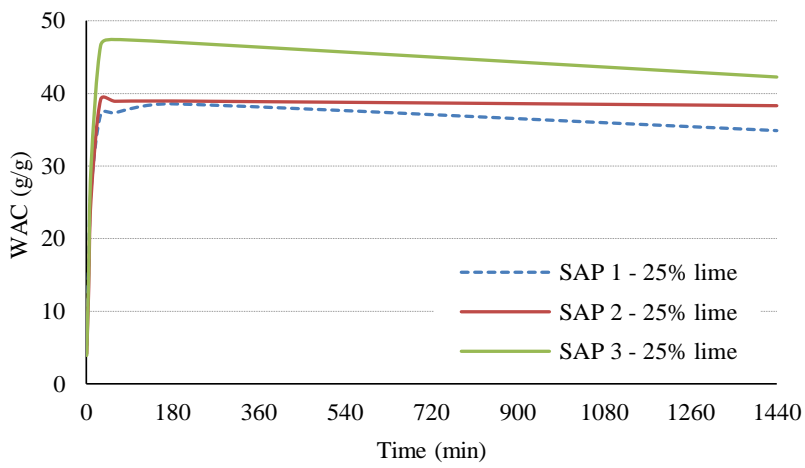

$50 \%$ lime

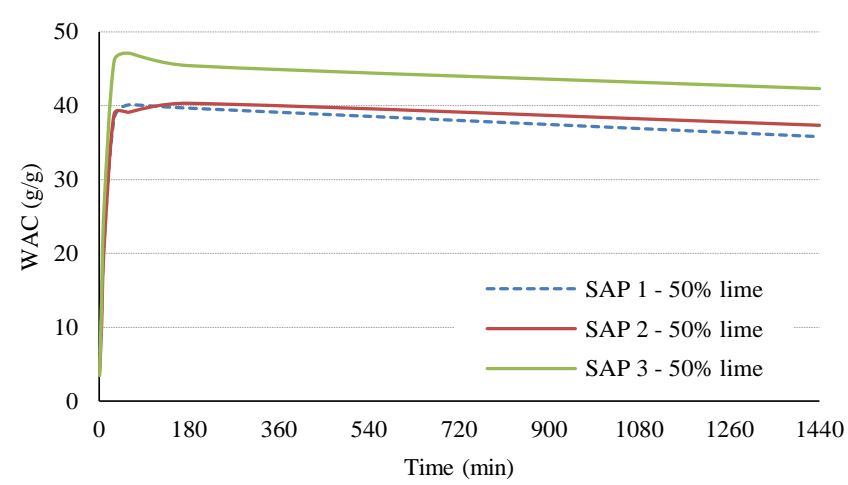

$75 \%$ lime

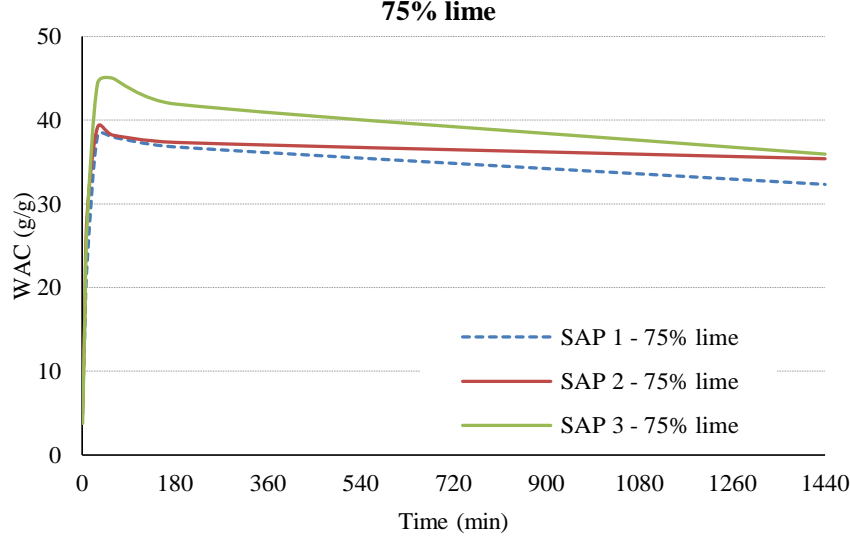

Fig. 8. Comparison of SAPs absorbency (left: up to 3h; right: up to 1 day) in different lime contents.

The above analysis confirms that not only the type of SCM can affect SAPs absorption capacities, but also the level of substitution. In particular, high SCMs contents result in the most significant changes.

In order to compare how different SCMs can affect SAPs performance, especially at high levels of substitution, a summary of water absorption capacities was shown in Figure 9. In general, SCMs addition leads to greater desorption compared to PC solutions. Plain cementitious system (without SCMs) results in the highest WAC for all SAPs; FA solutions, however, have the lowest WAC values. 


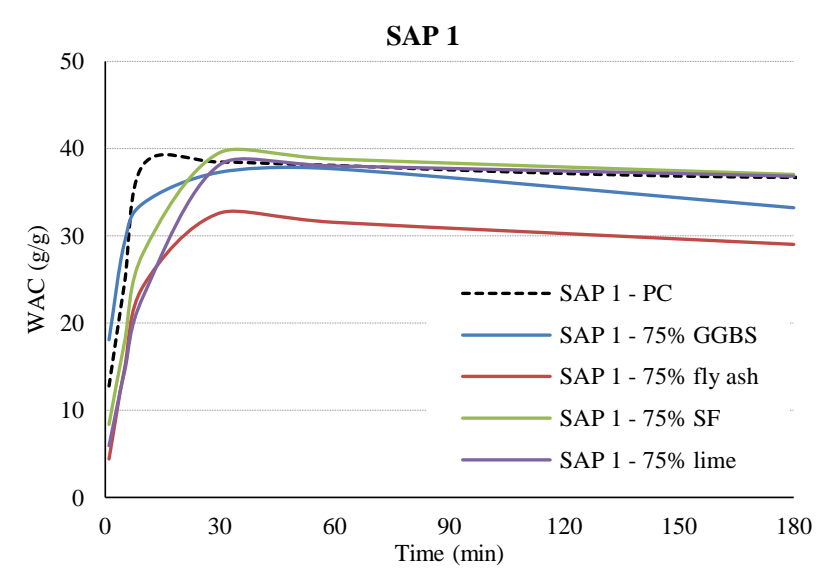

SAP 2

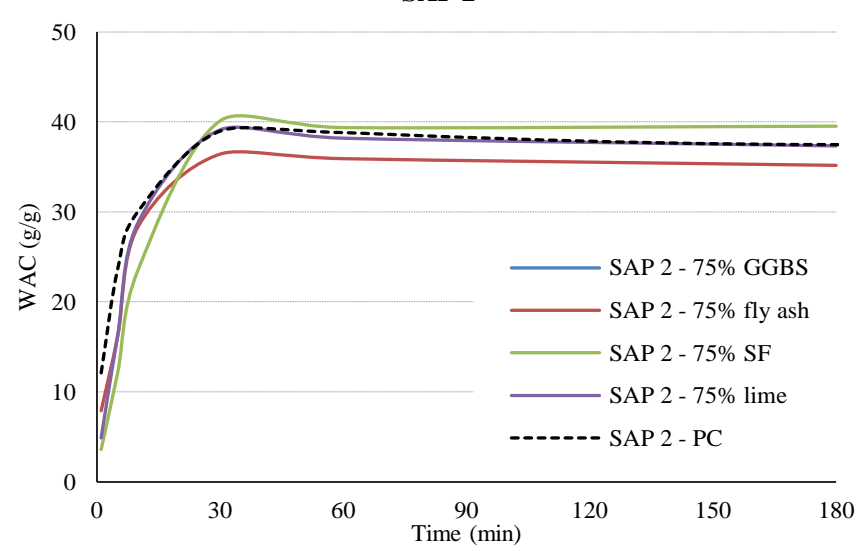

SAP 3

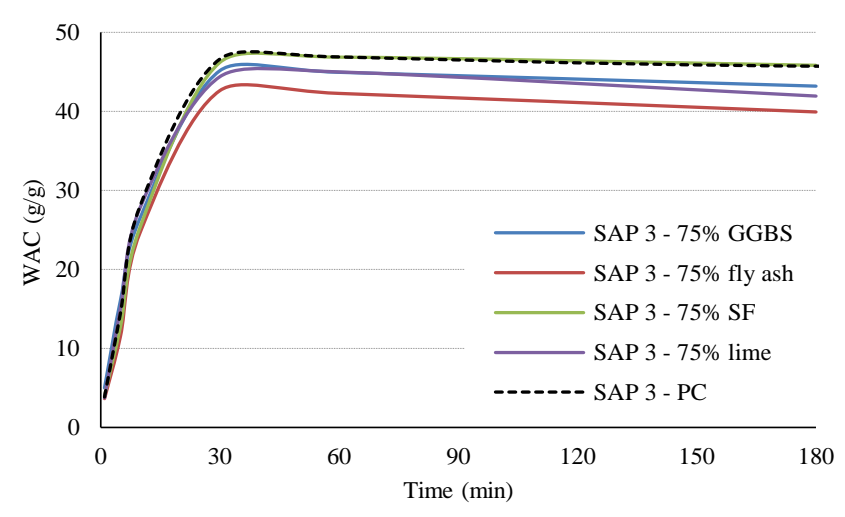

SAP 1

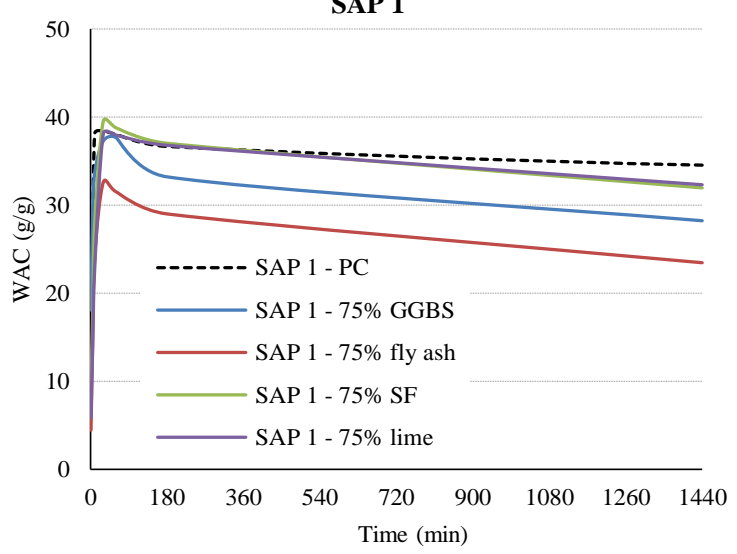

SAP 2

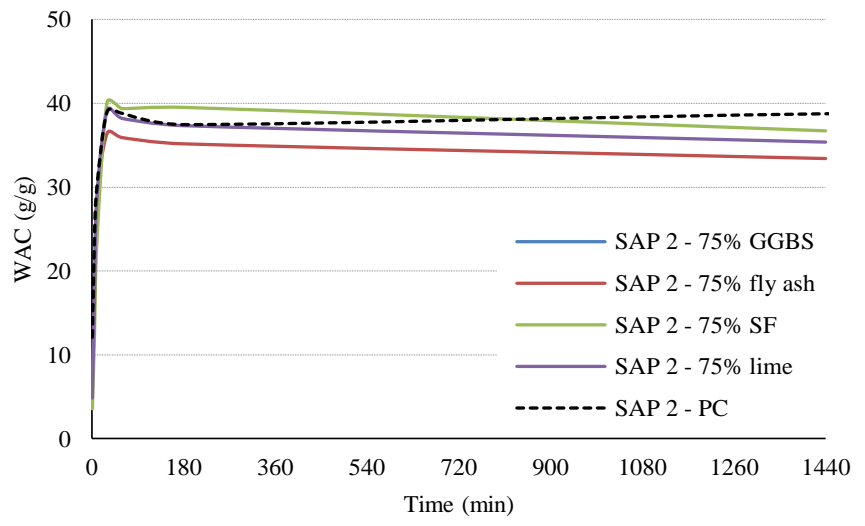

SAP 3

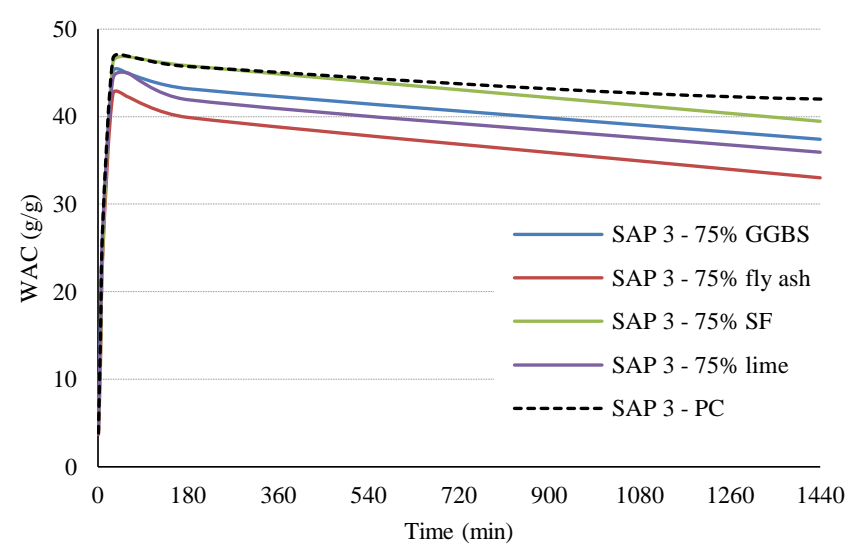

Fig. 9. Comparison of SAPs absorbency (left: up to 3h; right: up to 1 day) in different SCMs solutions with $75 \%$ of substitution

SAP 1 performs similarly in SF and Lime solutions. Also, during the first hours, absorptions in these both solutions is comparable to PC solution. Final WACs at 24h-test are 23, 28, 32 and $35 \mathrm{~g} / \mathrm{g}$ in FA, GGBS, SF, Lime and PC solutions, respectively.

SAP 2 has the highest capacity to store the same amount of water for longer periods, regardless the type of cementitious material used. Thus, this polymer is the least sensitive to the type of binder.
At the end of the test, WACs are about 33 and $38 \mathrm{~g} / \mathrm{g}$ for FA and PC solutions, respectively; for the rest of SCM's solutions, the results varies between $35-37 \mathrm{~g} / \mathrm{g}$. SAP 3 is very dependent on the SCM type, especially after $24 \mathrm{~h}$. Although SAP 3 has a comparable behaviour in SF and PC solutions within the first $3 \mathrm{~h}$, that polymer reached WAC values of $33,36,37,39$ and $42 \mathrm{~g} / \mathrm{g}$ at the end of the test for FA, Lime, GGBS, SF and PC, respectively. 
Table 3 shows $\mathrm{pH}$ results of solutions with (out) SAPs. Although SAPs have different $\mathrm{pH}$ in deionized water due to their own monomers compositions and concentrations, these differences become almost irrelevant in cementitious solutions after $24 \mathrm{~h}$.

Table 3. $\mathrm{pH}$ of solutions at $24 \mathrm{~h}$.

\begin{tabular}{l|cccc}
\hline Filtrate solution & Plain & SAP 1 & SAP 2 & SAP 3 \\
\hline DI water & 7.0 & 7.3 & 6.8 & 7.5 \\
PC & 12.7 & 12.8 & 12.8 & 12.7 \\
$75 \%$ GGBS & 12.2 & 12.1 & 12.3 & 12.2 \\
$75 \%$ FA & 11.5 & 11.5 & 11.5 & 11.6 \\
$75 \%$ SF & 11.7 & 11.7 & 11.7 & 11.7 \\
$75 \%$ Lime & 12.6 & 12.7 & 12.6 & 12.5 \\
\hline
\end{tabular}

The highest $\mathrm{pH}$ values were recorded for $\mathrm{PC}$ solutions, indicating that the presence of SCM's reduces alkalinity of cementitious systems. Since alkali concentrations in pore solution strongly depend on the total alkali content of $\mathrm{PC}$, this alkalinity usually decreases with increasing replacement of PC by SCMs. This is because alkalis incorporated in the glass fraction of SCMs are released more slowly than the alkalis from the cement (Vollpracht et al. 2016).

In the same context, the lowest $\mathrm{pH}$ was recorded for FA and SF solutions. This can be related to the lowest $(\mathrm{Ca}+\mathrm{Mg}) / \mathrm{Si}$ ratios (Table 1$)$, resulting in more alkalis take-up for their reactions. As a consequence, $\mathrm{pH}$ of the system is reduced (Hong and Glasser 1999; Vollpracht et al. 2016).

\section{Conclusions}

From the experimental analysis by the tea-bag method, the following can be concluded:

- SAPs' water absorption capacity is considerably reduced in cementitious solution with(out) SCM's compared to DI water;

- SCMs addition leads to greater desorption characteristics compared to PC solutions. SAPs have the highest WAC in plain cementitious system. FA solutions, however, lead the lowest WAC values;

- Usually, the higher SCM content the lower WAC;

- SAP C is the least sensitive to the type of cementitious solution. It is able to store more water for longer period of time;

- SAP 1 and 3 have significant desorption in cementitious solutions, especially with high SCM content;

- Although SAPs have different $\mathrm{pH}$ in DI water due to their own monomers compositions and concentrations, they do not affect alkalinity of cementitious solutions during the first day of test.Equations should be centred and should be numbered with the number on the right-hand side.

The authors acknowledge the National Council for Scientific and Technological Development $(\mathrm{CNPq}-$ Brazil $)$ for the financial support, and Dr Andrew Cowell for Laser Diffractometry analysis support.

\section{References}

Hong, S.-Y., and Glasser, F. P. (1999). "Alkali binding in cement pastes." Cement and Concrete Research, 29(12), 1893-1903.

Lothenbach, B., Scrivener, K., and Hooton, R. D. (2011). "Supplementary cementitious materials." Cement and Concrete Research, 41(12), 1244-1256.

Mechtcherine, V., and Reinhardt, H.-W. (Eds.). (2012). Application of Superabsorbent Polymers (SAP) in Concrete Construction: State-of-the-Art Report Prepared by Technical Committee 225-SAP. Springer, RILEM.

Mechtcherine, V., Snoeck, D., Schröfl, C., De Belie, N., Klemm, A. J., Ichimiya, K., Moon, J., Wyrzykowski, M., Lura, P., Toropovs, N., Assmann, A., Igarashi, S., De La Varga, I., Almeida, F. C. R., Erk, K., Ribeiro, A. B., Custódio, J., Reinhardt, H. W., and Falikman, V. (2018). "Testing superabsorbent polymer (SAP) sorption properties prior to implementation in concrete: results of a RILEM Round-Robin Test." Materials and Structures, 51(1), 28.

Mignon, A., Snoeck, D., Schaubroeck, D., Luickx, N., Dubruel, P., Van Vlierberghe, S., and De Belie, N. (2015). "pH-responsive superabsorbent polymers: A pathway to self-healing of mortar." Reactive and Functional Polymers, 93, 68-76.

Schroefl, C., Mechtcherine, V., Vontobel, P., Hovind, J., and Lehmann, E. (2015). "Sorption kinetics of superabsorbent polymers (SAPs) in fresh Portland cement-based pastes visualized and quantified by neutron radiography and correlated to the progress of cement hydration." Cement and Concrete Research, 75, 1-13.

Schröfl, C., Mechtcherine, V., and Gorges, M. (2012). "Relation between the molecular structure and the efficiency of superabsorbent polymers (SAP) as concrete admixture to mitigate autogenous shrinkage." Cement and Concrete Research, 42(6), 865-873.

Schröfl, C., Snoeck, D., and Mechtcherine, V. (2017). "A review of characterisation methods for superabsorbent polymer (SAP) samples to be used in cement-based construction materials: report of the RILEM TC 260-RSC." Materials and Structures, 50(4), 197.

Scrivener, K. L., Lothenbach, B., De Belie, N., Gruyaert, E., Skibsted, J., Snellings, R., and Vollpracht, A. (2015). "TC 238-SCM: hydration and microstructure of concrete with SCMs." Materials and Structures, 48(4), 835-862.

Siddique, R., and Khan, M. I. (2011). Supplementary Cementing Materials. Springer, Berlin.

Vollpracht, A., Lothenbach, B., Snellings, R., and Haufe, J. (2016). "The pore solution of blended cements: a review." Materials and Structures, 49(8), 33413367. 